\title{
The market triple
}

\author{
Stanisław Walukiewicz
}

Published online: 23 April 2013

(C) The Author(s) 2013. This article is published with open access at Springerlink.com

\begin{abstract}
It is a well known fact that at market equilibrium supply equals demand except for instance in North Korea and Europe during the Second World War. The above should be examined from a contemporary perspective (here and now) as well as all the accepted relevant terms, criteria and parameters. Basic terms such as value and market are redefined from this perspective and the organizer element is added. Thus a linear creation of demand and supply is expanded into a two-dimensional structure which provides the definition of a market triple. There are countless markets in the world around us, but only six market triples. Quite unique among the markets is the research market, our proposition for future developments.
\end{abstract}

Keywords Value Market - Market triple $\cdot$ Social capital $\cdot$ Formal and informal relations $\cdot$ Sharp and fuzzy boundaries

\section{Introduction}

It is not too much of a risk to state that as long as there will be civilization, there will be the exchange of goods and appropriate forums for these to take place, ie. a market game between demand and supply. Therefore we will examine the market economy under the equilibrium conditions where, grosso modo, demand $(D)$ equals supply $(S)$ :

$$
D=S
$$

Equation (1) is a relevant example of the present situation. It relates solely to market economies and has almost no relevance for countries like North Korea or Cuba, or

S. Walukiewicz ( $\square)$

Systems Research Institute, Polish Academy of Sciences, ul. Newelska 6, 01-447 Warsaw, Poland

e-mail: Stanislaw.Walukiewicz@ibspan.waw.pl 
Europe during the Second World War. It stands out in stark contrast, to for example the commonly accepted equation $2+3=5$. That said, we agree that (1) explains the reality of "here" (the market-economy part of the world) and "now" (present time). This paper shows that although (1) has been studied in a myriad of streams of books, papers and other writings there is still room for more research and investigation.

We first provide our definition of (1), which says that the (aggregated) value of demand equals the value of supply here and now. We provide broad definitions of value and market, respectively, in Sect. 2. In Sect. 3 we add the organizer (Org) to demand $D$ and supply $S$, and define the market triple. Then brief descriptions of six markets are provided (a green market, the NBA market, the research market, stock exchange, internal recruitment model and the market of informal relations) and their market triples studied. Quite unique among them is the research market, our proposition for the future-this market has a history yet to be written. In the concluding Sect. 5 we demonstrate, inter alia, that although there might be an infinite number of markets in the world, there are only six different market triples.

Demand and supply equality (1) is canonically used by economics scholars (see e.g. Samuelson 1955; Colander 1994; Parkin 2000; Mankiw and Taylor 2006) to demonstrate how market prices and production levels are established. We use (1) in a new way, as a here and now equation, describing how the market game between demand and supply is organized and played in different markets. The following example points out the originality of our approach.

\subsection{Introductory example}

We know that for any right-angled triangle with $a, b, c$ sides

$$
a^{2}+b^{2}=c^{2}
$$

Formally, (1) and (2) are alike and the left hand side equals the right hand side, but, in fact, they are sharply different. While the Pythagoras' theorem (2) is true everywhere and always, and does not concede exceptions, the very basic demand and supply rule (1) is valid in market economies (here) and for the present (now) only, plus it allows for exceptions (which prove it). Hence we suggest to consider a (mathematical) model of economic reality as a set of the here and now relations. To be more specific, consider the IS-LM model (Hicks 1937) which is commonly viewed as a summary of John Maynard Keynes' General Theory of Employment, Interest, and Money. The model describes the relationships between the goods and services market and the money market (see also Friedman 1997; Hicks 1980-1981). All equations used in the model follow from our main assumption (1) that demand equals supply on any market, which, as we demonstrated above, is the here and now equality. Therefore all equations of the IS-LM model are of the here and now type.

Since a detailed analysis of the IS-LM model or other models would make this paper unwieldy, it will be put off until a later time and finish this reasoning with the black swan paradox. It is said that the opportunity to see a black swan is minimal, yet possible, impressive if happens, and usually misjudged in hindsight. Translating it to 
the language of economics, it may be impossible to describe and express all things in mathematical terms and 'cooking up' formulas to predict every single possible outcome may be no other thing than creeping determinism. Hence the influence of mathematical models in economics is limited and the conclusions from such models should be considered with some caution. In our methodology things seem to look easy: swans are white and the occurrence of black variants proves this rule here and now.

\section{Definitions of value and market}

A frequently used word in modern culture - in many different contexts - is "value". There is the value of goods and services, there are human values, artistic value, moral value, value of a human life, etc. So anything in the world has its value. We do not purport, though, that all present valuations are correct and note that it is hard to forge a one-line definition of "value", just as it is hard to tersely define "time" or "quality" (though we all know too well what "lack of time" or "lack of quality" is). Here in this section we first provide a broad definition of value, then proceed to discuss it.

Definition 1 A value is an economic equivalent of anything around the world here and now.

This means that anything in the world (a product, service, idea, professional basketball player, emotion, etc.) has its own value, mostly measured here and now in monetary units. Definition 1 may be interpreted using so-called economic scales. If an apple costs one dollar here and now, then the economic scales are balanced if we put that apple on one side and a dollar bill or four quarters or ten dimes, etc. on the other. This means that one dollar is the economic equivalent of the apple here and now. Materially, an apple is heavier and occupies more space than a dollar bill, in which lies the difference between the economic equilibrium and the physical one.

Equilibrium is the state of balance. From Definition 1 one may conclude then that in the world around us that little is free and can be taken for granted. Present day Greece is a painful example of that obvious, yet often overlooked truth.

The following proposition brings together the concepts of value and market.

Proposition 1 A value, be it naturally created or (theoretically) constructed, is always fixed or defined in a market.

It is accepted that the value (of almost anything in the world) is the amount of money-we call it "economic equivalent"- that someone is ready to pay (for) in a market. In Proposition 1 we emphasis the word "always" since the value of a given 'inventory' (item, idea, etc.) cannot be assessed outside its market. If we would like to measure e.g. the extent (or the value) of welfare of a given country, we need first to construct a model of, say, the domestic welfare market that will include all the country's resources (assets), be they tangible or intangible.

Any exchange on a market may be considered as a result of a market game between demand and supply. We now propose a broad and applicable definition of a market. 
Definition 2 A market is a set of rules of a market game between demand and supply. Such rules are approved here and now as fair, reasonable and adequate, and regulate how (1) should be understood on a here and now basis.

It appears that the term "adequate" is critical to Definition 2. A set of rules is adequate if its cardinality equals the minimum number of rules necessary to make the activity (game) of a given market workable here and now. The situation when there are not enough rules seems controllable. As life moves on, there will always be market actors (people) to catch up and add the missing laws or procedures. It appears that the opposite alternative is much more challenging, cf., for instance, the painstaking efforts made in some countries to deregulate labour markets.

The market rules are reasonable if they can successfully stand the test of a legal trial here and now, for example, a lawsuit on a property market between a home buyer and a developer. Meanwhile, since referring every market transaction to the court is impractical, unrealistic, and also foolish, fairness is added as yet another pre-condition of market rules. Obviously, fair means fairness on a here and now basis.

\section{The definition of a market triple}

We propose to add the third element - an organizer $(\mathrm{Org})$ — to the traditional model of demand $D$ and supply $S$ and study relations and boundaries between them. The next section explains via examples the meaning of sharp and fuzzy boundaries between these three elements, bearing in mind that only formal and informal relations exist between people.

Definition 3 A market triple consists of three focal points: demand $D$, supply $S$ and organizer $\mathrm{Org}$. Relations between them are formal and/or informal, and boundaries sharp and/or fuzzy.

Graphically, a market triple is a triangle (see Fig. 1). As a provider of the market game, the organizer is placed above the $D S$ base. Circles are used for vertices instead of points to incorporate names of particular market actors. Formal and informal relations between a pair of vertices are pictured as solid lines or dashed lines, respectively. Straight crossing double lines represent sharp boundaries, whereas wavy double lines are used to mark fuzzy boundaries.

The demand $D$, placed in the bottom left-hand corner, plays a creative role in (1) first people think, dream, visualize a purchase, and to complete it they should have sufficient funds. It corresponds to the lesson learnt from physics: action first, then reaction. Furthermore, when mathematical equations are constructed, the unknowns go to the left (idea of purchase not yet fully realized) and constants to the right side of the equality sign (purchase materialised). Hence, and in accordance with the way a text in e.g. English is read, demand $D$ is always on the left and supply $S$ on the right at the base of the market triple (Fig. 1). Accordingly, in the expression "demand-supply", the order matters.

The above three definitions have a ground-breaking nature as they provide new tools for the analysis of reality here and now and form a base for two-dimensional 


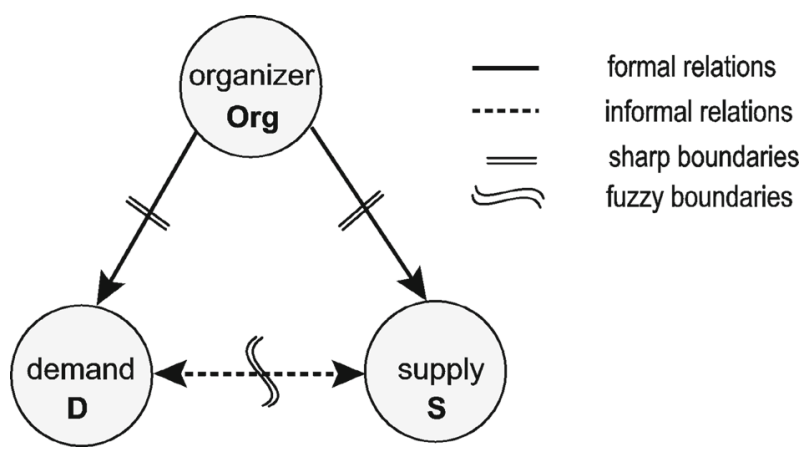

Fig. 1 A market triple-universal model

economics (see Fig. 1) vis-á-vis a traditional, one-dimensional conception based on the assumption that demand equals supply.

\section{Examples}

\subsection{Green market}

From the beginning of civilization, the organizer Org of a green market has largely been based on common sense, telling people where and when to organize a fair, how to put up stalls, to make them accessible for customers (demand $D$ ) and the ease for sellers to operate (supply $S$ ), etc. Today's organizer may operate within an organizational framework, supported by e.g. local administration, police, fire safety service, etc. Among other duties, the organizer regulates the activity of buyers and sellers. So the relations between the organizer and demand or supply are formal as exhibited by solid arrows from $\mathrm{Org}$ to $D$ or $S$ in Fig. 2. Someone buying a kilo of apples does not sign a formal contract with a seller; there must be a certain amount of trust between them, where trust probably should be ranked as the most important informal relation between people. Then, the public come to a fair not only to buy but also to chat with each other or a vendor. So relations between demand $D$ and supply $S$ are informal—see double arrowed dashed line as a base of the market triple in Fig. 2. The boundaries between the organizer, demand and supply, respectively, are sharp (straight double crossing lines in Fig. 2), as their roles in a green market are sharply different.

The market triple of a green market looks like an equilateral triangle. One may argue at this point that boundaries between demand and supply are not sharp enough because a seller may sometimes buy something in his/her marketplace. In fact, it only proves the rule of a green market here and now. As anyone, a buyer or seller comes and acts in a green market as a free, conscious and fully responsible individual, then he/she agrees that its rules are fair and reasonable and adequately account for the equality of demand and supply here and now. 


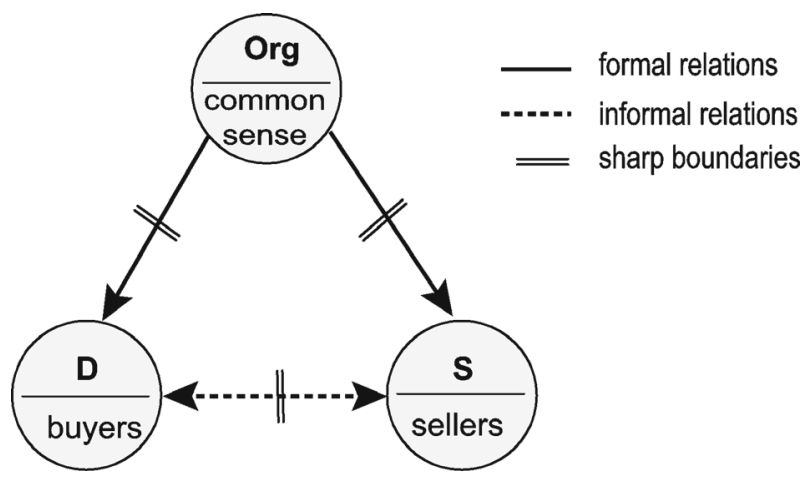

Fig. 2 The market triple of a green market

\subsection{The NBA market}

The NBA market is an example of a constructed market, created in the USA by the National Basketball Association 40-50years ago. Amongst others, the rules of the NBA market regulate the flow of professional basketball players between the NBA clubs. One such rule caps the amount of spending a club can afford on new players in a given year. The limit on a club's spending is set to prevent a situation when a rich club buys top professionals and wins (almost) all games. The NBA is flexible; should a need arise, it alters the rules for games to make them more attractive for fans and TV audiences as the NBA market is tightly connected with the market of sports emotions. For the need of our analysis, we combine these two markets into one and jointly call the NBA market. Basketball fans, not only in the USA, trust the NBA as a key player in the designing/organizing of sports emotions market and find its rules fair, reasonable and adequate.

We use the NBA market as an example because its achievements have been and are still spectacular. There are 30 clubs in the NBA and if we assume that there are 100 top men (players, coaches, managers etc.) in each club, then the 3,000 people generate the turnover of some four billion dollars a year, which makes the NBA market one of most efficient in the world. Many national sports associations consider NBA as a good, professional example, look up to it with respect and try to adopt its model.

A type of merchandise largely offered on the NBA market are sports emotions. Most fans (demand $D$ ) pre-purchase tickets, buy season tickets or subscribe to paid TV services well before games arranged by the clubs (supply $S$ ) begin. It all happens according to the schedule and requirements established by the NBA (organizer Org). Here, we note a two-level supply model: the association at the upper level and clubs at the lover (see Fig. 3). For obvious reasons the relations between NBA and fans or clubs must be formal and boundaries sharp, whereas the relations between fans and clubs are informal (fans love their clubs and vice-versa). Interestingly enough, the boundary between clubs and fans must remain sharp, as only clubs report to the NBA on their business (see double oriented line as the S-Org side in Fig. 3).

Now we show briefly that a political emotions market, connected with parliamentary or presidential elections, forms exactly the same market triple as above. At election 


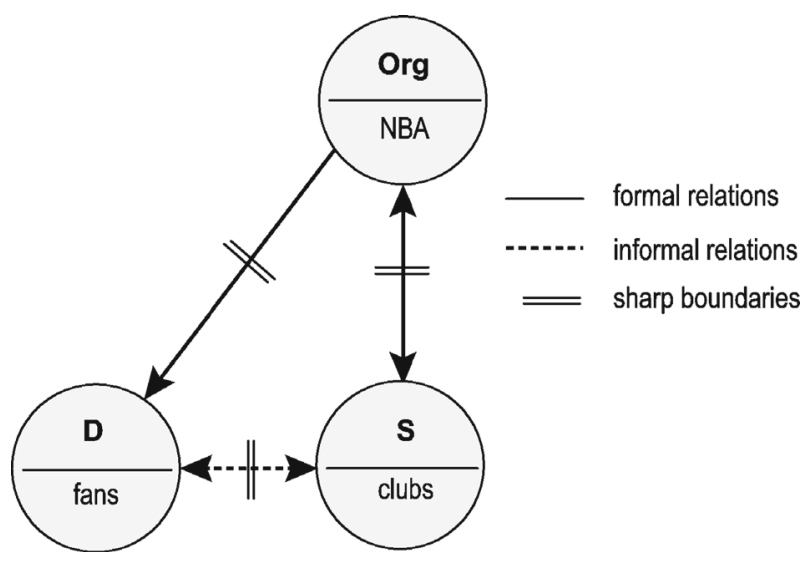

Fig. 3 The market triple of the NBA market

time a voter (demand) would choose (buy) a party or politician from among their likes, all soliciting his/her vote during the election campaign. To see how it works, return to Fig. 3 and make the following substitutions: "legislative bodies" (The Supreme Court, Congress, etc. in the USA) for NBA, voters for fans and political parties/politicians for clubs. It can easily be inferred that that relations and boundaries in the political emotions market are exactly the same as on the NBA market. Thus, the market triples of both markets are alike. Perhaps it explains why, normally, elections are not held during important sports events, such as Olympic Games, World Cups, etc.

The market triple for sports or political emotions forms a triangle with the right angle at supply $S$.

\subsection{Research market}

An idea for such a market as a consistent, logical structure has not been brought to life yet and the following should be considered as the author's (theoretical) contribution.

The idea is as follows: research output - to be introduced to the research market - is commissioned by its organizer $\mathrm{Org}$ (governmental funding agencies, private funding institutions, etc), who runs (or issues or solicits) calls for proposals. Scientists and experts etc. (supply $S$ ) respond to a call by forming a project team and writing a proposal. Bidders may come from all over the world, but due to legal (formal) regulations relating to money transfer, taxes, etc., and for practical reasons, must be affiliated to or set up under the auspices of a legal research institution (university, research centre, etc.), which together with the organizer forms a two-level demand model: founding agencies as an organiser Org on the upper level and research institutions on the lower-see Fig. 4. Obviously, relations between the actors are formal with clearly defined boundaries. All sides of the market triple in Fig. 4 are double-oriented lines, which means that communication between the actors runs in both directions. Although the project team does all the reporting to the organizer via its research institution, the team shall be required to provide immediate feedback right to the organizer to enable 


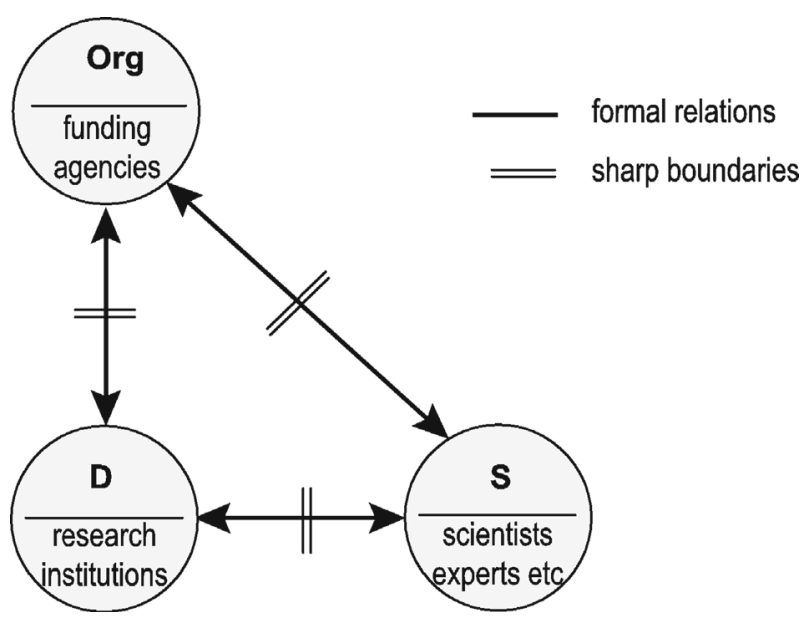

Fig. 4 The market triple of a research market

the latter to include it when designing further calls. Also, the organizer informs the scientific community (to form later project teams) about the calls, their objectives, requirements, etc., - as dictated by the rules of the research market—see Definition 2. Thus, the market triple for the research market looks like a triangle with the right angle at demand $D$ as shown in Fig. 4.

There are certain similarities between the research market and the NBA market. We believe that top specialists at the NBA headquarters are not ruthless bureaucrats hoarding money and scraping points together but real basketball fanatics and, more importantly, experts who can immediately recognize the talent of a player. It seems to me that the organizer of a research market should play the role of a service provider and a controlling body on the one hand, setting requirements, schedule, etc. (NBA as an organisation) and that of a coach and master on the other, selecting best project teams to a market game described in a call for proposals (NBA as people). Once a team submits a proposal, this means that its members accept the rules of the research market game as fair, reasonable and adequate, cf. Definition 2.

The organizer selects project teams at "present" taking into account their performance in the "past" to obtain the best results in the "future". The duration of each such phase depends heavily on a particular call Typically, the selection ("present") takes a couple of months, while the background ("past") refers to years, and the output "future" has usually a 2-5 year horizon. In extreme cases the "past" and the "future" may be unlimited, and the "present" last for a moment. We conclude that the "present" may be a boundary line between the "past" and the "future" and the three phases always exist in a decision making process regarding a research market, as well as any market.

We note that the research market is a unique market with a two-level demand model, perhaps never known so far. Furthermore, it has two very distinctive properties. First, its demand is concentrated, whereas its supply is scattered, just contrary to the green market and the sports or political emotions markets studied above. Secondly, the research market is open, while the two other are closed. To clarify this phenomenon we 
shall look briefly into the green market. Let us assume, without the loss of generality, that all products brought to it are meant to be sold during a single trading day. If something remains unsold, we may take that it is bought by a dummy buyer and, conversely, a missing product is sold by a dummy seller. We can do so because the economy as a whole is in equilibrium and, by (1), demand equals supply. The missing product may just as well be delivered to the market on the next trading day or so. Validity of such reasoning may easily be verified by the example of sports or political emotions markets. Hence, the green market and the emotions markets are of a closed type.

Generally speaking, the results of any research activity can be grouped into three main categories:

(i) New products and/or services. They leave a research market and enter a products/services market which has its own market triple.

(ii) New procedures, for example medical, legal procedures, etc. As above, they enter a new market (services).

(iii) Educated people. They leave a research market or an education market and enter a labour market.

This clearly illustrates that unlike the green or the emotions markets which are closed, the research market is open. This finding should be considered as a new approach to market economy analysis (point ii) above) or two-dimensional economics, developed under the UE project "Human Capital and Social Capital as New Academic Subjects", coordinated by the author (see Walukiewicz 2012).

\subsection{Stock exchange}

For the purpose of this study, we consider the simplest version of the stock exchange, where dealers buy and sell stocks almost simultaneously. The same actors play a market game on both demand $D$ and supply $S$ and the boundaries between $D$ and $S$ are fuzzy: they can easily be crossed either way, as illustrated by double wavy lines in Fig. 6a. The relations between demand and supply are informal—see dashed double-oriented arrow as a base of the market triple in Fig. 6a. An organizer Org sets and executes the rules of trading stocks. The primary rule says that dealers have equal access to information about stocks. Obviously, relations between the organizer and demand and supply are formal and boundaries sharp.

It follows from the above that demand and supply in stock exchange are combined since the same actors can play on either side and the boundaries between them become fuzzy. Let us now describe a reduction (procedure) for market triples. If in a given market two actors $A$ and $B$ are informally related to each other and boundaries between them are fuzzy, that means that they can easily interchange their roles. Then we substitute them with a combined A/B actor (their reduced equivalent). Figure 5 illustrates the reduction of a side of a market triple.

If we apply this procedure to the market triple in Fig 6a, then we receive the market triple of the stock exchange (after reduction), as shown in Fig. 6b. It is shaped as a vertical segment. 


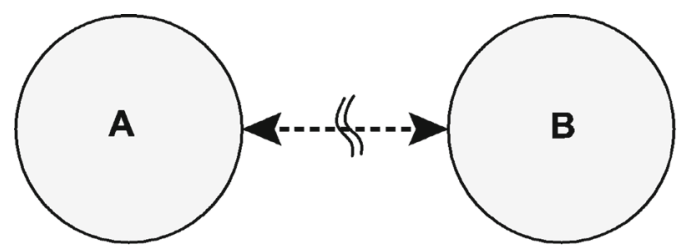

(a)

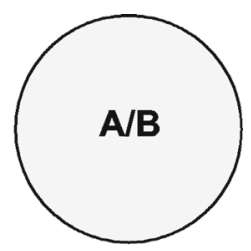

(b)

Fig. 5 An illustration of reduction procedure. a Before reduction, $\mathbf{b}$ after reduction

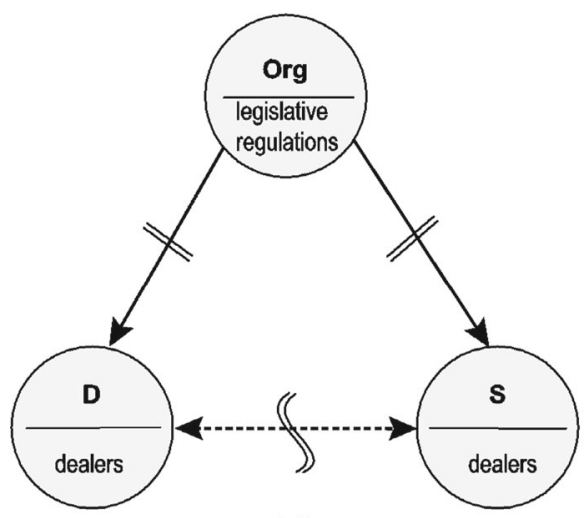

(a)

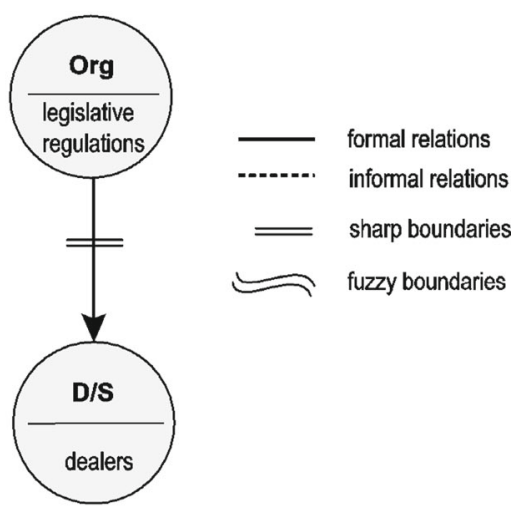

(b)

Fig. 6 The market triple of stock exchange. a Before reduction, $\mathbf{b}$ after reduction

Definition 4 A market triple is reducible if it allows reduction. The relevant market is reducible, too.

Wherefore, stock exchange is reducible, whereas the green market, the emotions market and the research market are irreducible.

\subsection{Internal recruitment}

If the management of a given firm announces a new position, then it may look for an appropriate worker on the internal labour market by organizing and running an internal recruitment procedure. The management itself or an internally specially appointed committee, which closely though informally cooperates with them, is an organizer Org that defines rules, requirements, etc. for that procedure. On the other side of the equation are workers - candidates who offer as supply $S$ their abilities, experiences, talent, etc. This means that the candidates consider the above rules as fair, reasonable and adequate (Definition 2). With the committee referred to above, there is two-level demand: the committee (management) at the upper and the management at the lower level, as shown in Fig. 7a. The boundary line between them is fuzzy, while all other boundaries are sharp. If we apply reduction to side $\mathrm{Org}$ - $\mathrm{D}$ in Fig. 7a, then we obtain the 


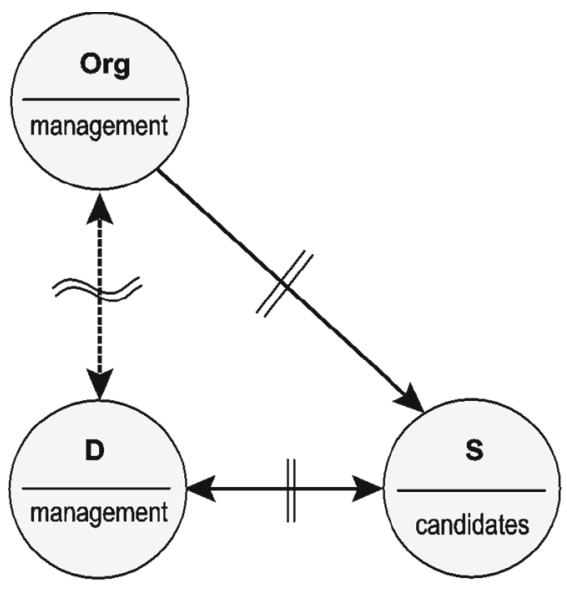

(a)
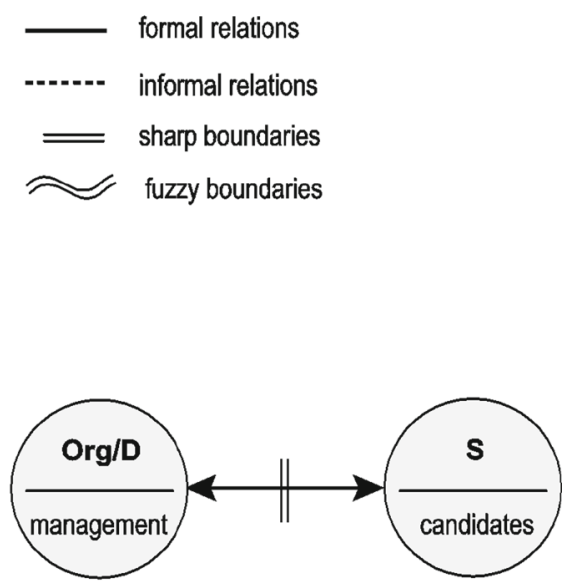

(b)

Fig. 7 The market triple of internal recruitment. a Before reduction, $\mathbf{b}$ after reduction

market triple of internal recruitment shown in Fig. 7b. Thus, internal labour market or internal recruitment is reducible and its market triple reduces to a horizontal segment.

If the internal recruitment procedure is successful, the management signs a contract with the selected candidate and the internal labour market (for that position) vanishes. As an alternative, the management may look in (external) labour market.

\subsection{Informal relations market}

Finally, we will look into the intimate world of a couple John and Mary as an example of an informal relations market. If anyone doubts that this 'venture' is scientifically justified, we can only say that millions of Johns and Marys or such markets contribute to world economies. Moreover, the findings are very interesting.

In our (Western) culture, relations between John and Mary are informal and boundaries are fuzzy as shown in Fig. 8a. Exceptions like formal contracts for divorce, death certificates, etc. only prove that statement here and now. They jointly or separatelyas the organizer $(\mathrm{Org}$ ) — set and/or modify the rules of the informal relations market. Since John and Mary act as free, fully accountable individuals, they accept the rules set as fair, reasonable and adequate-see Definition 2. Suppose John buys a rose on a green market, at a price of $\$ 5$, and offers (sells as supply $S$ ) it to Mary who has dreamed about it as demand $D$. Even though the rose has a clear pecuniary value, it is priceless for them in their intimate world, or on their informal relation market. Hence, the same 'inventory' (item, emotion, etc.) may have a different price across markets.

If we twice apply the reduction procedure to Fig. 8a, then we arrive at Fig. 8b, which shows the market triple of the informal relations market. So the market triple of an informal relations market is a single point. It can be obtained in three different ways, depending on which side of the market triple in Fig. 8a the reduction procedure begins with. 


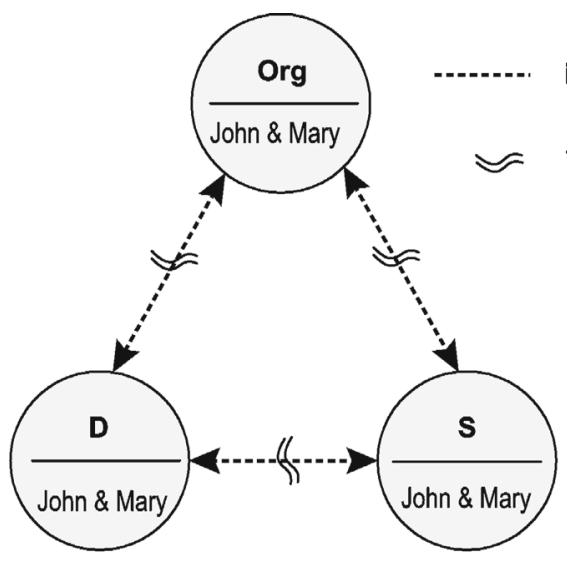

(a)

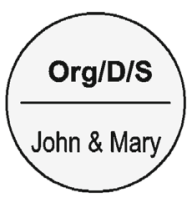

(b)

Fig. 8 The market triple of the informal relations market. a Before reduction, $\mathbf{b}$ after reduction

Observation 1 A single individual will not form a market, but two individuals will.

Our amiable couple, John and Mary form the smallest possible market. Observation 1 coincides widely with the following definition of social capital (Walukiewicz 2008): social capital is all formal and/or informal relations between at least two individuals considered as free and fully accountable.

Again, it has been demonstrated that markets can be found everywhere; in fact, there are infinitely many of them.

We are now ready to draw two conclusions.

Conclusion 1 No market exists without social capital.

In other words, social capital lies in the heart of any market. Given that markets are everywhere, the rules of market regulate our life from birth (market for pampers) to death (market for funeral services). As markets are everywhere, so is social capital. Then as a new academic subject it will be tightly connected with the two-dimensional economics (see Walukiewicz 2012). Social capital has been extensively studied in the last 15-20 years. There are more than 10,000 publications on that subject in data bases like ProQuest, Sociofile and SocioINDEX.

Conclusion 2 Only people can form a market.

This conclusion is a hard statement of fact in the face of growing popularity of all kinds of fads and fallacies in the name of science. A good example is a false impression of the growth of so called high-speed trading (HST), where sophisticated and powerful computers sell and buy stocks at a stock exchange. Conclusion 2 leaves no doubt: this is not true. Skilled people programme such computers and set/modify the rules of the market involved, leaving computers the role of nothing but tools in the process.

The above conclusions demonstrate the main difference between classical, onedimensional economics and our two-dimensional concept. Classical economics is the 
science of choices - it is centred around five big questions regarding man-made goods and services: What? How? When? Where? and Who? (see Parkin 2000, p. 2). Nowadays more and more goods and services are produced by robots, automata, computer programs, etc., and man is but negligible in the process. So 'who?' is becoming dramatically less important in the equation. Two-dimensional economics has other pursuits. It studies formal and informal relations between active actors of many tightly connected markets. Here, humans are considered as creators of rules governing such markets and the rules must be fair, reasonable and adequate here and now.

To finish this subsection we consider a (scientific) seminar as the place of information exchange and show that the market triple for it perfectly matches that for informal relations in Fig. 8a. Usually, a seminar is chaired by a person with some authority (organizer $\mathrm{Org}$ ). A lecturer (supply $S$ ) presents (sells) a paper or a piece of information to interested listeners (demand $D$ ). At the same or later seminars, the actors often interchange their roles (a listener becomes a lecturer and vice versa, an organizer presents a lecture, etc.). Boundaries between them are fuzzy and relations informal as shown in Fig. 8a. Since, in general, people chat about politics more often than participate in scientific seminars, let us introduce the so called market of clean politics. On such a market, people exchange (informally) information. Its market triple is given in Fig. 8a, and can be reduced to a single point as in Fig. 8b.

It was almost as far back as in the beginning of civilization that people observed that information is more effectively exchanged in the presence of an authority, organizer Org of a market of clean politics as we call it. Being an organizer (authority) entails extra privileges: he/she can manage or manipulate people on either side of demandsupply, may have respect, additional gratification, etc. Many try to play the role of an organizer for as long as possible and change the informal relations with demand and supply into formal ones, as well as fuzzy boundaries into sharp ones. So, gradually, step by step Fig. 8a (market of clean politics) gets changed into Fig. 6a. We call the latter a market of dirty politics. Surprisingly, the market triple for dirty politics is the same as the one for stock exchange (Fig. 6a) and it can be reduced to the vertical segment shown in Fig. 6b. The political career of Adolf Hitler in Germany before the Second World War is a well known example of transition from a market of clean to dirty politics.

Conclusion 3 Politics is a composition (mixture) of clean and dirty politics.

It is regretable that there are countries whose politics is dirtier than in others. Politics as a way of organizing our life depends heavily on the proportion of rules that govern markets of clean and dirty politics, respectively (see Definition 2).

\section{Conclusions}

1. All the above market triples can be viewed as a result of continuous mappings of a triangle. Depending on whether the three vertices of a triangle are distinct points or some of them coincide, three (topological) images of a triangle exist: a triangle itself, a line segment and a single point. As explained in Sect. 2, up-down and left-right orientations were introduced. Therefore we distinguish between a 
triangle with the right angle at demand (research market) and a triangle with the right angle at supply (sports or political emotions market), as well as between a vertical line segment (stock exchange) and a horizontal line segment (internal recruitment). So, practically speaking, there are infinitely many different markets, as markets are everywhere, but only six different market triples. Three of them are irreducible (green market, emotion market and research market) and the other three reducible (stock exchange, internal recruitment and informal relations market).

2. The research market is a unique market with a two-level demand model, perhaps never known before. It bears certain similarities to the NBA market developed 40-50 years ago (see Sect. 4.3). Let us add two more points here. First, generally speaking, social-economic development tends to be viewed as an endless improvement of the division of labour and knowledge. We suggest to start discussion on the division of labour, knowledge and pleasure. The NBA market demonstrates how huge a turnover can be generated from one particular type of emotions (pleasure) and shows how to organize it (Sect. 4.2). We claim that a developed research market will bring in a bigger, much bigger turnover. Second, it looks like the NBA market integrates American society. For instance, the national basketball team of the USA is called the dream team. We generalize the above observation as a conclusion that market integrates, whereas its absence disintegrates.

3. Different markets interact and influence each other under market economy conditions. Any market is a living structure, brought to life, changed and modified by people with all their merits and faults. For instance, there was a big conflict (lockout) between organizer and supply on the NBA market in 2011 and the 2011/12 season begun well after the set date. In my personal opinion not all changes are for the better. Clean and dirty politics markets are good examples. In Sect. 4.6 we show how a market of clean politics becomes smudged and dirty. This happens so because many are those who prefer half a minute TV spots to half an hour seminar, with a tendency to make the former last even shorter. We conclude that without people's active participation politics will become more dirty and democracy weaker.

4. Science repeatedly asks two fundamental questions: First 'Why?' and second 'How much?' For instance, why we constantly talk about inflation (too much money in the economy), but not about overproduction (too many products in it). Our very brief answer is: because we can with relative ease measure the demand for any product/service here and now, but not for money, a very specific "product", an economic equivalent of anything around the world as was said in Definition 1. Therefore, let us turn to the second fundamental question of how much? That is, how much money should be put into an economy here and now not to overheat it on the one hand, but also not to see it frozen. To answer the first fundamental question above we may apply the input-output analysis and study the relevant piece of reality as a black box with its inputs (reasons) and outputs (effects). An answer to the first fundamental question may be illustrated by the lighting of the black box. It seems natural that to find a key to the second fundamental question we need to construct an appropriate market triple with its actors (demand, supply and organizer), relations and boundaries. Here, it would be more appropriate to 
consider it as the lighting of a 'grey box'. The lighting of the black box as well as the lighting of the grey box will be a challenging subject for further studies.

Acknowledgments I am grateful to Professor Ulrike Leopold-Wildburger, Editor-in Chief of CJOR, and two anonymous referees for their comments on the first version of the paper.

Open Access This article is distributed under the terms of the Creative Commons Attribution License which permits any use, distribution, and reproduction in any medium, provided the original author(s) and the source are credited.

\section{References}

Colander DC (1994) Economics. Irwin, Illinois

Friedman M (1997) John Maynard Keynes. Econ Q 83(2):1-23

Hicks JR (1937) Mr. Keynes and the classics: a suggested interpretation. Econometrica, pp 147-159 http:// www.policonomics.com/wp-content/uploads/Mr.Keynes-and-the-Classics.pdf

Hicks J (1980-1981) IS-LM: an explanation. J Post Keynes Econ 3(2):139-155

Keynes JM (1936) The general theory of employment, interest, and money. Macmillan, London

Mankiw NG, Taylor MP (2006) Economics. Thomson Learning, London

Parkin M (2000) Economics, 5th edn. Addison Wesley, Reading

Samuelson PA (1955) Economics, 3rd edn. McGraw-Hill, New York

Walukiewicz S (2008) The Dimensionality of social capital and proximity. In: Proceedings of ERSA 2008, Liverpool, August 27-30

Walukiewicz S (2012) Kapitał społeczny, (in Polish, Social Capital), Systems Research Institute, Polish Academy of Sciences, Warsaw. See also the project's website: http://www.noweklks.ibspan.waw.pl/ 